\title{
The Expansion Motor of Tarek Soukar Is a Real Global Warming Reducer
}

\author{
Tarek R. Socar \\ Tarek Socar Establishment, T4, Island 4, Dommar Project, Damascus, Syria
}

\begin{abstract}
Global warming matter is a word problem. Most solutions are preventative; they only avoid or reduce the heat emissions to the minimum. The natural solution for global warming matter is to increase vegetation. However, no industrial treatment to solve this problem has been invented yet. One great idea to solve this problem is to convert the extra heat to another shape of power. This method can really reduce global warming. Expansion Motor of Tarek Soukar represents this technical method.The expansion motor has not been addressed before, it is a new invention. It was supposed to be a solar engine, but it has proved that it is not limited to the Sun, but can be run by any other existing heat. All engines and motors are heat diffusers, while the expansion motor is a heat absorbent. As a result, with such a solution global warming is not a problem anymore, it became a new resource of power. Researchers and manufacturers are requested to start adopting, developing, producing this motor and spreading it widely.
\end{abstract}

\section{Introduction}

Global warming became a serious problem and an international issue. Many worst case scenarios were presented around the world.

The Paris climate agreement — the nonbinding, unenforceable and already unheeded treaty signed on Earth Day in 2016 - hoped to restrict warming to two degrees. The odds of succeeding, according to a recent study based on current emissions trends, are one in 20. If by some miracle we are able to limit warming to two degrees, we will only have to negotiate the extinction of the world's tropical reefs, sea-level rise of several meters and the abandonment of the Persian Gulf. The climate scientist James Hansen has called two-degree warming "a prescription for long-term disaster." Long-term disaster is now the best-case scenario. Three-degree warming is a prescription for short-term disaster: forests in the Arctic and the loss of most coastal cities. Robert Watson, a former director of the United Nations Intergovernmental Panel on Climate Change, has argued that three-degree warming is the realistic minimum. Four degrees: Europe in permanent drought; vast areas of China, India and Bangladesh claimed by desert; Polynesia swallowed by the sea; the Colorado River thinned to a trickle; the American Southwest largely uninhabitable. The prospect of a five-degree warming has prompted some of the world's leading climate scientists to warn of the end of human civilization. [1]

Human activities since the industrial revolution started the problem. The discovery of fossil fuels (cool, oil and gas) led to different types of combustion engines. However, after more than 100 years of use, they started consuming the sources of this fuel which had harmful effects on the environment like pollution and global warming. This led to the necessity for an engine of a clean and renewable energy and a motor that can make good use of these resources, saving the fossil fuels and keeping it long for the future generations. All combustion engines and even electrical motors are heat diffusers, expensive, limited in power, and have poor efficiency. These engines need high precision in manufacturing, and have to bear great heat and pressure, which are exclusive for advanced industrial countries. However, the expansion engine is a heat reducer and an environmental breakthrough in generating power. It can be operated at normal temperatures, low pressures, and can be manufactured even with poor industrial technologies .

\section{Previous methods, proposed methods, experiments, analysis, comparison and results.}

Previous methods. With the global warming issue, most efforts are theoretical solutions, or preventative methods.

Theoretical solutions. The United Nations adopted several procedures dealing with the global warming issue and climate changes challenge. The first is the establishment of relevant international organizations, such as: IRENA, IPCC, IEA, IUCN, UNEP, ... Etc. These have been able to diagnose the problem but have not been able to address it. The second is the awareness and guidance conferences, binding and non-binding agreements, such as:(COP1.2...........21 ). In his article " The Paris Agreement and the new logic of international climate politics " Robert Falkner states:

This article reviews and assesses the outcome of the 21st Conference of the Parties (COP-21) to the United 
Nations Framework Convention on Climate Change (UNFCCC), held in Paris in December 2015. It argues that the Paris Agreement breaks new ground in international climate policy, by acknowledging the primacy of domestic politics in climate change and allowing countries to set their own level of ambition for climate change mitigation. It creates a framework for making voluntary pledges that can be compared and reviewed internationally, in the hope that global ambition can be increased through a process of 'naming and shaming'. By sidestepping distributional conflicts, the Paris Agreement manages to remove one of the biggest barriers to international climate cooperation. It recognizes that none of the major powers can be forced into drastic emissions cuts. However, instead of leaving mitigation efforts to an entirely bottom-up logic, it embeds country pledges in an international system of climate accountability and a 'ratchet mechanism', thus offering the chance of more durable international cooperation. At the same time, it is far from clear whether the treaty can actually deliver on the urgent need to de-carbonize the global economy. The past record of climate policies suggests that governments have a tendency to express lofty aspirations but avoid tough decisions. For the Paris Agreement to make a difference, the new logic of 'pledge and review' will need to mobilize international and domestic pressure and generate political momentum behind more substantial climate policies worldwide. It matters, therefore, whether the Paris Agreement's new approach can be made to work. [2]

Preventative procedures. These procedures work on producing the heat emissions. They include the decrease of deforestation, the increase of vegetation and by the use of renewable energy. They also include methods like: recycling, antipollution systems, automotive vehicles, start stop engines, and green wave traffic lights....etc. All of the previous solutions and efforts have accomplished so little in comparison with the fast increase of global warming. We can't keep watching and do nothing, a serious and fast action must be done. We have either to stop heating, or to start cooling our planet. Both options are not really able to be accomplished.

Proposed method. The proposed method, The expansion motor of Tarek Socar, is a new invention. It converts heat into action by leaving the causes of global warming and managing the results. It gets rid of the extra heat by converting it into action.

Summary of the invention. The invention is a method or a device that converts thermal expansion, and contraction, of objects or liquids into action. It consists of a set of cylinders containing the active ingredient (substance or expansion liquid). Each of the cylinders is connected to an arm and a motion element (or a piston lever). All are assembled on a rotatable block. When one of the cylinders is exposed to a change in temperature, the kinetic power - caused by liquid's stretching or shrinking - pushes the connected arm to collide with a slanted wall. This slanted wall is designed to provide a reaction force moving the arm with its cylinder and piston to place a new group of (cylinder- piston- arm) in the place of the previous group. So the motion is recreating itself again and again.
The patent. This new invention is a new type of motors that has got the patent in 2016 ,Syrian Application No. 5087.

Prizes and Participations. The Expansion Motor of Tarek Soukar won the silver medal in the 10th International Exhibition of Inventions 3ed World Invention and Innovation IEI \&WILF 2018 -CHINA. It participated in the international Sheikh Zayed prize UAE and in the national Albasel exhibition.

Detailed explanation. We bring a group of dark cylinders $(\mathrm{C} 1, \mathrm{C} 2, \mathrm{C} 3, \ldots, \ldots)$ with high heat absorption ability. These cylinders contain an element (L) with a large volumetric dilation coefficient. The cylinders are provided with pistons $(\mathrm{P} 1, \mathrm{P} 2, \mathrm{P} 3, . . . . ., .$.$) , which are$ connected to transmission beams i.e. plungers ( $\mathrm{B} 1$,B2 , B3 , ....... ) , and all of the previous parts are assembled on a rotatable block. (Fig.1) The cylinders at the top are exposed to The Sun, while the cylinders down are drowned in a cooling pool. When the cylinder( $\mathrm{C} 1)$ reaches the active point, the exposed to heat area, the expansion of the active liquid (L) inside will push the related piston ( $\mathrm{P} 1$ ) moving the plunger ( B1)to hit a slanted shock wall ( A ) which is fixed on the axis of the rotatable block. A reaction force pushes the plunger, cylinder, piston, and the whole rotatable block to round them all around the axis. The rotation will start and will place a new group of (cylinder C2, piston $\mathrm{P} 2$, and plunger B2) in the area exposed to heat. This action will happen again and again. To reduce the friction with the slanted shock wall, a cylinder bearing can be added on top of each transmission beam sliding on the slanted shock wall. A cooling stage is needed to return the piston to its principle position. Here we can improve the design of the slanted shock wall to a helical shock wall. By doing this, we get another reaction force during the contraction phase, which is another rotating force in the same direction. (Fig.1) We can also add a parabolic reflector mirrors to concentrate the solar heat on the position of the active cylinder. (Fig.2) Actually the collection of these cylinders plungers and Pistons fixed on a rotatable block will give us a continuous rotation which is simply the expansion motor. A prototype is executed using a set of thermostats as the active elements. (Fig.3,4,5,6)

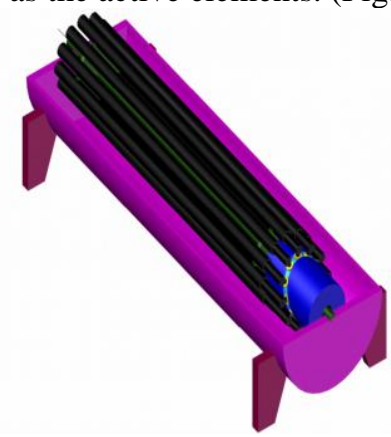

Figure 1. The expansion motor of Tarek Soukar 


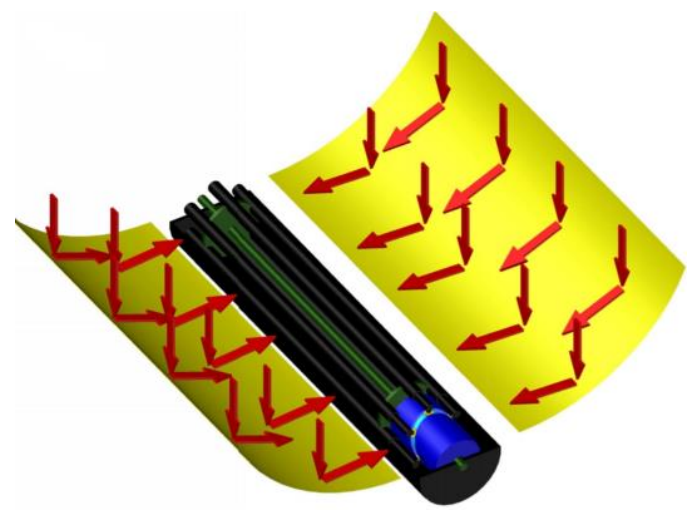

Figure 2. The motor with parabolic reflector.
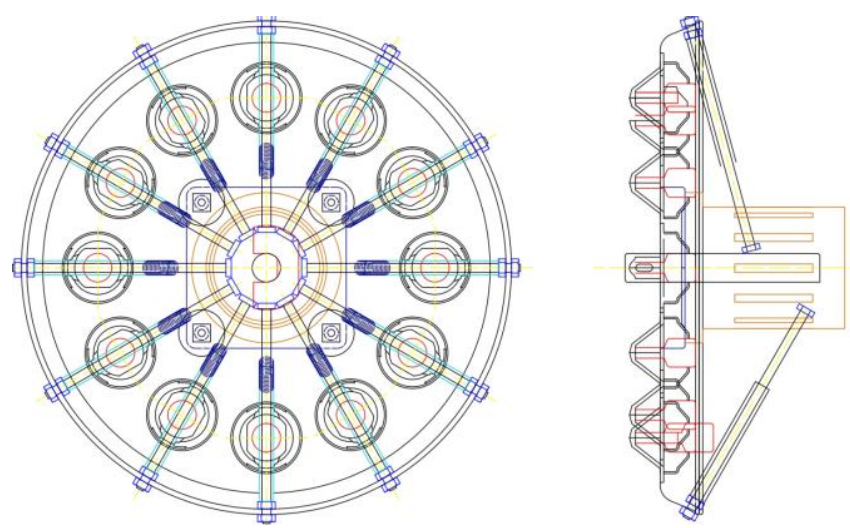

Figure 3. The prototype ( plan ).

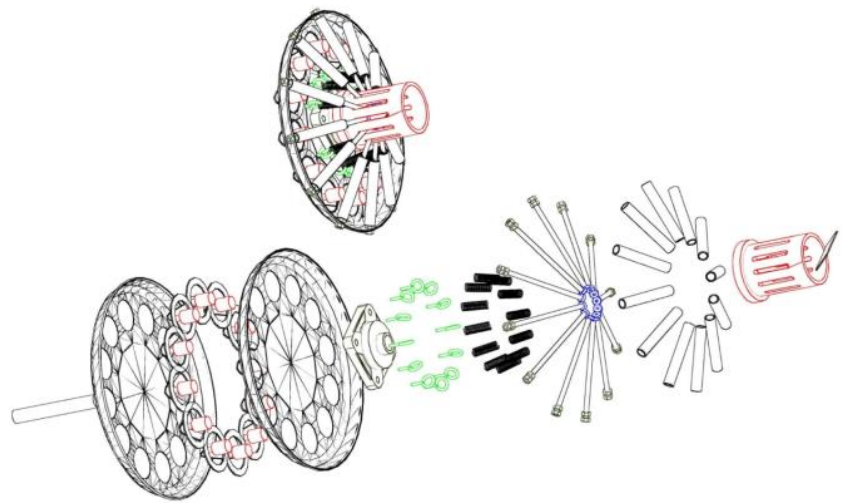

Figure 4. The prototype ( parts )
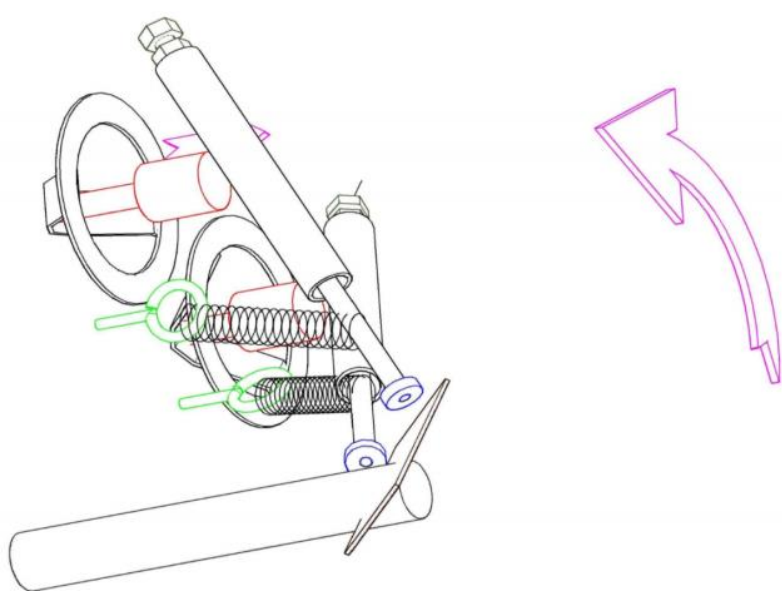

Figure 5. The prototype ( The action )

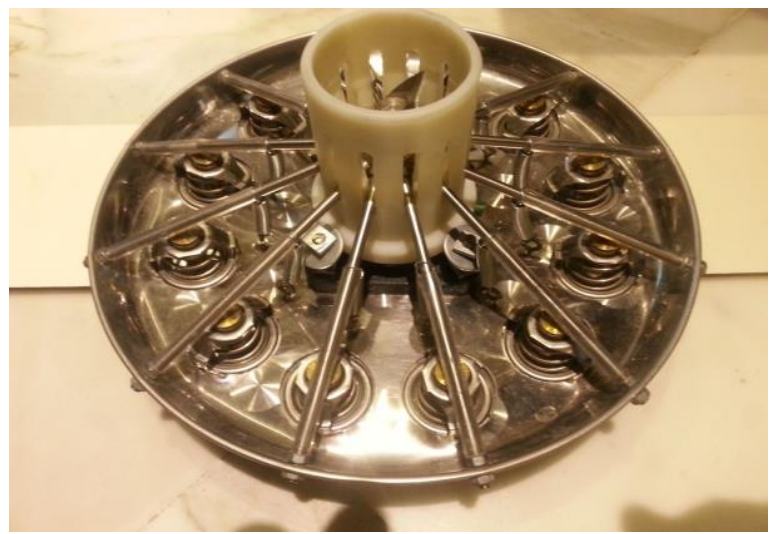

Figure 6. The prototype (photo)

\section{Experiments}

Parameters and some mechanical calculation of the first expansion motor, a general descriptions of the prototype and contents. The prototype consists of :

2 steel dishes, 12 thermostats, 12 chrome rods, 12 string, 12 cylinder bearings, 1 metal axis,

1 slanted metal sheet, 1 square bearing, 1 special shaped plastic cylinder, some screws and clutches.

The outer dimensions is about $25 \mathrm{~cm}$ diameter, $15 \mathrm{~cm}$ thick.

The heating capacity is about 150-300 Watts ( 3 vacuum tubes ).

The force (pushing strength) of each thermostat is F1 $=65 \mathrm{Kg}$ (not exactly).

$\mathrm{d} 1, \mathrm{~d} 2$ are the two distances of the effecting points on the chrome rod of the arms.

$\mathrm{d} 1=12 \mathrm{~cm}, \mathrm{~d} 2=3 \mathrm{~cm}$.

The force (pushing strength) on the slanted metal sheet $\mathrm{F} 2$ can be calculated with the equation:

$\mathrm{F} 2=\mathrm{F} 1 \times \mathrm{d} 2 / \mathrm{d} 1, \mathrm{~F} 2=65 \times 3 / 12=16 \mathrm{Kg}$.

$\mathrm{A}$ : is the torque arm which equals $=2.5 \mathrm{~cm}=0.025 \mathrm{~m}$.

The rotating torque can be calculated with the equation :

$\mathrm{T}=\mathrm{F} 2 \times \mathrm{A}, \mathrm{T}=16 \times 0.025=0.4(\mathrm{Kg} . \mathrm{m})$.

This will increase two times if we gain the contracting stage force. The rpm (rotation per minute) is too small, it 
varies due to the shape of the slanted metal sheet, in our case experimentally it is in the range of (1-2 ) rpm.

\section{Analysis}

Three main benefits of the expansion motor: it converts (Low-solar thermal energy) into mechanical action, improves efficiency, and reduces the temperature.

The expansion motor converts Low-solar thermal energy into mechanical action.

Before the invention of the expansion motor no converting of the low-temperature solar power into action was possible. This now can be easily done.

Two types of Solar Energy, Photovoltaic and Thermal. Photovoltaic technology directly converts sunlight into electricity. Solar thermal technology harnesses its heat. These different technologies both tap the Sun's energy, locally and in large-scale solar farms.

Like water and air, the Sun is one of the Earth's life support systems, providing heat and light. Solar energy, which is renewable, widely available and clean, provides enough energy to meet the world's annual consumption needs every 50 minutes. The challenge is to collect a share - however small - of this heat and radiant energy. [3]

Solar thermal technology captures the sun's heat. This heat is used directly (low temperature solar thermal) or converted into mechanical energy and in turn electricity (concentrated solar power - CSP). The expansion motor modifies the calcification of solar thermal energy. (Fig.7)

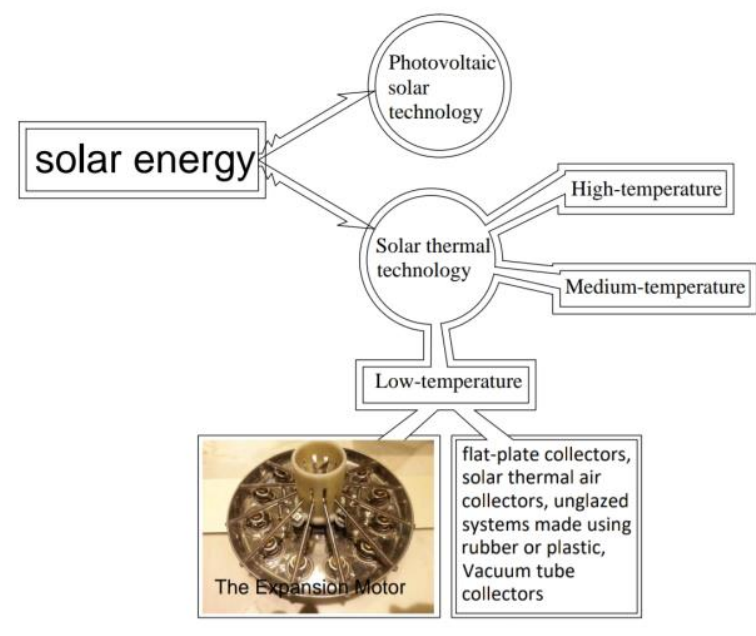

(Fig . 7)

Figure 7. A new calcification of solar thermal energy

Solar thermal collectors are classified by the United States Energy Information Administration as low-, medium-, or high-temperature collectors. Lowtemperature collectors are generally unglazed and used to heat swimming pools or to heat ventilation air. Mediumtemperature collectors are also usually flat plates but are used for heating water or air for residential and commercial use. High-temperature collectors concentrate sunlight using mirrors or lenses and are generally used for fulfilling heat requirements up to $300 \mathrm{deg} \mathrm{C} / 20 \mathrm{bar}$ pressure in industries, and for electric power production. a PV collector will only convert about $12 \%$ of the sunlight into electrical energy on average. A general rule of thumb is that the energy available from the sun is about $1 \mathrm{~kW}$ per square meter. This translates to about $3400 \mathrm{BTU} / \mathrm{hr}$ per square meter. If you can get $70 \%$ of that heat using thermal solar collector, then you would only need about 42 square meters (450 sq. $\mathrm{ft}$ ) to generate as much heat as a typical home's gas furnace $(100,000$ $\mathrm{BTU} / \mathrm{hr}$ ). Another advantage is that solar thermal panels only cost a small fraction (about 20\%) of what PV panels cost per square meter. When you combine 6 times the efficiency with 5 times better pricing, you get something that is 30 times better, right? Well, not exactly. [4]

The conversion into action is possible now with any temperature this allows us to harness the $70 \%$ of the sun energy with low temperature $\leq 100 \mathrm{deg}$ C. (Fig7)

\section{The expansion motor improves efficiency.}

Engine cycle inefficiencies. The efficiency formulas (Otto cycle: automobiles - Diesel cycle: trucks and trains - Rankine cycle: steam power plants - Brayton cycle: gas turbines and jet engines ) are based on simple idealized mathematical models of engines, with no friction and working fluids that obey simple thermodynamic rules called the ideal gas law. Real engines have many departures from ideal behavior that waste energy, reducing actual efficiencies far below the theoretical values given above. Examples are:

- friction of moving parts

- inefficient combustion

- heat loss from the combustion chamber

- departure of the working fluid from the thermodynamic properties of an ideal gas

- aerodynamic drag of air moving through the engine

- $\quad$ energy used by auxiliary equipment like oil and water pumps.

- inefficient compressors and turbines

- imperfect valve timing

Another source of inefficiency is that engines must be optimized for other goals besides efficiency, such as low pollution. The requirements for vehicle engines are particularly stringent: they must be designed for low emissions, adequate acceleration, fast starting, light weight, low noise, etc. These require compromises in design (such as altered valve timing to reduce emissions) that reduce efficiency. The average automobile engine is only about $35 \%$ efficient, and must also be kept idling at stoplights, wasting an additional $17 \%$ of the energy, resulting in an overall efficiency of $18 \%$. Large stationary electric generating plants have fewer of these competing requirements as well as more efficient Rankine cycles, so they are significantly more efficient than vehicle engines, around $50 \%$ Therefore, replacing internal combustion vehicles with electric vehicles, which run on a battery that is charged with electricity generated by burning fuel in a power plant, has the theoretical potential to increase the thermal efficiency of energy use in transportation, thus decreasing the demand for fossil fuels.

When comparing different heat engines as sources of power, such as electric power or the power to run 
vehicles, the engine efficiency alone is only one factor. To give a meaningful comparison, the overall efficiency of the entire energy supply chain from the fuel source to the consumer must be considered. Although the heat wasted by heat engines is usually the largest source of inefficiency, factors such as the energy cost of fuel refining and transportation, and energy loss in electrical transmission lines to transport it, may offset the advantage of a more efficient heat engine.

Two benefits are obtained by adding the expansion motor to heat engines. The first is that it will increase the efficiency by converting the output emissions to mechanical power, then to electrical power with generators. The second is that it will reduce the heat emissions, so it is not necessary to design engines for low emissions anymore.

Currently most of the nuclear power stations must operate below the temperatures and pressures that coalfired plants do, in order to provide more conservative safety margins within the systems that remove heat from the nuclear fuel rods. This, in turn, limits their thermodynamic efficiency to $30-32 \%$. Some advanced reactor designs being studied, such as the very-hightemperature reactor, Advanced Gas-cooled Reactor, and supercritical water reactor, would operate at temperatures and pressures similar to current coal plants, producing comparable thermodynamic efficiency.[6]

The high temperature steams and gases produced from these stations can be passed through the expansion motor to reconvert heat into action again. Even if we didn't generate electrical power by the added expansion motor we would be at least converting the extra heat into action and reducing heat emissions.

The expansion motor reduces the temperature.

In the following lines we are going to calculate the stored calories in our planet, only in the oceans, as following: Water amount in the oceans and seas is almost about 300 $\mathrm{x} 10^{15}$ ton of water. For $3 \mathrm{deg} \mathrm{C}$ reduction, the stored calories are about :

$3 \times 300 \times 10^{15} \times 10^{6}=900 \times 10^{21}$ calories.

Billions of calories which are stored in our oceans can be converted into power by the expansion motors, any little difference in temperature between water and air above, can operate the expansion motors and create an action. Liquids such as mercury, alcohol, gasoline and any element with large volumetric dilation coefficient can rise the performance and the activity of the expansion motors, if they are used as an active elements. Other billions of calories are also stored in our environment and lands, the calculation here is much complicated but the same results could be reached.

\section{Comparison}

The previous methods have been able to diagnose the problem but have not been able to address it. Previous efforts were unable to reduce or even to put limits to the global warming. While the new offered method, the expansion motor, is an active industrial solution, it reduces temperature, creates free power, then generates electric or provides action.
(Heat engines transform thermal energy, or heat, $Q_{\text {in }}$ into mechanical energy, or work, $W_{\text {out }}$. They cannot do this task perfectly, so some of the input heat energy is not converted into work, but is dissipated as waste heat $Q_{\text {out }}$ into the environment ). [7]

All engines and motors are heat diffusers, while the expansion motor is a heat absorbent. By this new invention global warming will not be a problem anymore, it can be considered as a new resource of power.

\section{Results \& Conclusions}

The expansion motor has not been addressed before. Any little difference in temperature can create an action. We can convert heat into action, either with the solar power or with any exciting heat. The billions of calories which are stored in our environment, our oceans and lands can be converted into useful power. This is also a new method to generate electric power harnessing the lowtemperature solar thermal. Liquids such as mercury, alcohol, gasoline and any element with large volumetric dilation coefficient are useful active elements, and can rise the performance and the activity of the expansion motor.

The expansion motor can operate separately, and can be provided to all the following devices;

a) (Otto cycle: automobiles - Diesel cycle: trucks and trains - Rankine cycle: steam power plants Brayton cycle: gas turbines and jet engines ).

b) The top of each vehicle can be a good solar thermal collector.

c) The roof of each building and the exposed to Sun facades can also be suitable.

d) Street columns and advertising columns which are good options to install solar equipments.

e) Sea constructions and ships. rivers and riversides, ice and water under ice.

At the end, this is a request for all researchers and manufacturers to take this invention seriously, and to start a race developing, producing and spreading it widely.

\section{References}

1. Losing Earth: The Decade We Almost Stopped Climate Change By Nathaniel Rich Photographs and Videos by George Steinmetz AUG. 1,2018

https:/www.nytimes.com/interactive/2018/08/01/ma gazine/climate-change-losing-earth.html

2. The Paris Agreement and the new logic of international climate politics ROBERT FALKNER International Affairs, Volume 92, Issue 5, 1 September 2016, Pages 1107-1125, https://doi.org/10.1111/1468-2346.12708 Published: 31 August 2016

3. The Two Types of Solar Energy, Photovoltaic and Thermal Creation date 21 Nov. 2014 https://www.planeteenergies.com/en/medias/close/two-types-solarenergy-photovoltaic-and-thermal. 
4. What's Better, Solar Thermal or Solar PV?By John Kinnear, https://www.solarpowerauthority.com/whats-bettersolar-thermal-or-solar-pv/

5. Thermal efficiency From Wikipedia, the free encyclopedia, https://www.princeton.edu/ssp/61tiger-cub/library/efficiency.pdf
6. Thermal power station From Wikipedia, the free encyclopedia,

https://en.wikipedia.org/wiki/Thermal_power_station

7. Thermal efficiency From Wikipedia, the free encyclopedia 